\title{
Correction to: Comparison of Clinical Outcomes Between Surgical Gastrostomy and Percutaneous Endoscopic Gastrostomy with Introducer Technique in Patients with Upper Aerodigestive Malignancies: A Single-Center Analysis
}

\author{
Bancha Ovartlarnporn ${ }^{4} \cdot$ Varayu Prachayakul ${ }^{5}$ \\ Published online: 11 May 2020 \\ (C) Société Internationale de Chirurgie 2020 \\ Correction to: World J Surg \\ https://doi.org/10.1007/s00268-020-05532-z
}

Arunchai Chang ${ }^{1} \cdot$ Chomduan Watcharamon $^{2} \cdot$ Attapon Rattanasupa $^{1} \cdot$ Kittikarn Thongsonkleeb $^{2}$ - Bunlue Chowdok ${ }^{2}$ - Araya Khaimook ${ }^{3}$.

In the original version of this article, there were data missing from Table 3. Following is the corrected Table 3. The original article has been updated.
Publisher's Note Springer Nature remains neutral with regard to jurisdictional claims in published maps and institutional affiliations.

The original article can be found online at https://doi.org/10.1007/ s00268-020-05532-z.

Varayu Prachayakul

kaiyjr@gmail.com

1 Division of Gastroenterology, Department of Internal Medicine, Hatyai Hospital, Songkhla, Thailand

2 Department of Surgery, Hatyai Hospital, Songkhla, Thailand

3 Division of Minimally Invasive Surgery, Department of Surgery, Hatyai Hospital, Songkhla, Thailand

4 Faculty of Medicine, NKC Institute of Gastroenterology and Hepatology, Songklanagarind Hospital, Prince of Songkla University, Songkhla, Thailand

5 Siriraj Gastrointestinal Endoscopy Center, Division of Gastroenterology, Department of Internal Medicine, Faculty of Medicine, Siriraj Hospital, Mahidol University, Bangkok 10700, Thailand 
Table 3 Univariate and multivariate logistic regression analysis of predictors of in-hospital procedure-related major complications associated with gastrostomy tube placement

\begin{tabular}{|c|c|c|c|c|}
\hline \multirow[t]{2}{*}{ Factor } & \multicolumn{2}{|c|}{ Univariate regression analysis } & \multicolumn{2}{|c|}{ Multivariate regression analysis } \\
\hline & Odds ratio $(95 \% \mathrm{CI})$ & $P$ value & Odds ratio $(95 \% \mathrm{CI})$ & $P$ value \\
\hline BMI, per 1 unit increase & $0.90(0.81-0.99)$ & 0.041 & $0.92(0.82-1.03)$ & 0.164 \\
\hline Underlying disease & $1.91(0.65-5.64)$ & 0.242 & & \\
\hline Location of malignancies & & 0.394 & & \\
\hline Head and neck & 1.00 (reference) & & & \\
\hline Esophagus & $1.60(0.55-4.67)$ & & & \\
\hline Hemoglobin $<11 \mathrm{~g} / \mathrm{dL}$ & $4.0(1.35-11.86)$ & 0.012 & $2.95(0.81-10.70)$ & 0.101 \\
\hline Albumin $\geq 3 \mathrm{~g} / \mathrm{dL}$ & $0.18(0.04-0.82)$ & 0.026 & $0.21(0.04-1.29)$ & 0.093 \\
\hline Procedure & & 0.006 & & 0.011 \\
\hline Surgical gastrostomy & 1.00 (reference) & & 1.00 (reference) & \\
\hline Introducer technique PEG & $0.12(0.03-0.54)$ & & $0.11(0.02-0.61)$ & \\
\hline
\end{tabular}

